Cristian Kunusch • Paul Puleston • Miguel Mayosky

\title{
Sliding-Mode Control of PEM \\ Fuel Cells
}

包 Springer 


\section{Contents}

1 Introducing Fuel Cells $\ldots \ldots \ldots \ldots \ldots$

1.1 An Outlook of the Energy Perspective . . . . . . . . . . . 1

1.2 What is a Fuel Cell? . . . . . . . . . . . . . . 3

1.3 State-of-the-Art on Fuel Cell Systems Technology . . . . . . . . 3

1.3.1 Fuel Cell Units . . . . . . . . . . . . . . . . . . . 4

1.3.2 Fuel Cell Stacks . . . . . . . . . . . . . . 5

1.3.3 Auxiliary Components . . . . . . . . . . . 6

1.4 A Brief History of Fuel Cells . . . . . . . . . . . . . 6

1.5 Closed-Loop Operation of Fuel Cells. Why? . . . . . . . . . 9

1.6 Scope and Outline of the Book ... . . . . . . . . 10

References ........................ 10

2 PEM Fuel Cell Systems $\ldots \ldots \ldots \ldots$

2.1 An Introduction to PEM Technology . . . . . . . . . . . . 13

2.2 Basics of PEM Fuel Cells Operation . . . . . . . . . . . . . 14

2.3 Efficiency and Power Conversion . . . . . . . . . . . . 17

2.4 State-of-the-Art in PEM Fuel Cells Technology . . . . . . . . . 18

2.5 Components and Associated Devices . . . . . . . . . . . . 19

2.5.1 Polymeric Membranes . . . . . . . . . . . . 19

2.5 .2 Electrodes . . . . . . . . . . . . . . 20

2.5 .3 Gas Diffusion Layers . . . . . . . . . . . . 21

2.5 .4 Sealing Gaskets . . . . . . . . . . . . . 22

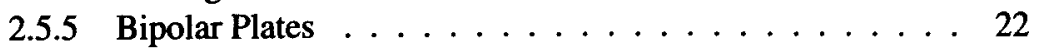

2.5.6 Auxiliary Devices . . . . . . . . . . . . . . . 24

2.6 Available PEM Fuel Cell Models in the Open Literature . . . . . 27

2.6.1 Control Oriented Models . . . . . . . . . . . 28

2.6.2 Control Objectives and Challenges . . . . . . . . . 29

2.6.3 Recent Advances on PEM Fuel Cell Control . . . . . . . 30

References ....................... 31

3 Fundamentals of Sliding-Mode Control Design . . . . . . . . 35

3.1 Introduction ....................... 35 
3.2 Variable Structure Control Preliminaries . . . . . . . . . . . 35

3.3 Fundamentals of Sliding-Mode Control . . . . . . . . . . . . 36

3.3.1 Diffeomorphisms, Lie Derivative and Relative Degree . . . 37

3.3.2 First-Order Sliding Mode . . . . . . . . . . . . . . . 39

3.3.3 Equivalent Control Regularisation Method. Ideal Sliding Dynamics ... . . . . . . . . . . . . 40

3.3.4 Existence Conditions for the First-Order Sliding Regime . . 42

3.3.5 Extension to Nonlinear Systems Non-affine in Control . . . 45

3.3.6 Filippov Regularisation Method . . . . . . . . . . . 45

3.3.7 Discontinuous Control Action in Classic Sliding-Mode Control. Chattering Problem . . . . . . . . . . . . . . 47

3.4 Some General Concepts on Higher-Order Sliding Modes . . . . . . 48

3.4.1 Definition of Differential Inclusion . . . . . . . . . . 49

3.4.2 Sliding Modes on Manifolds ............ 50

3.4.3 Sliding Modes and Constraint Functions. Regularity Condition ................. 51

3.4.4 Closing Comments on Higher-Order Sliding Modes in Control Systems . . . . . . . . . . . . . . 53

3.5 Design of Second-Order Sliding-Mode Controllers . . . . . . . . 54

3.5.1 Second-Order Sliding Generalised Problem . . . . . . . . 54

3.5.2 Solution of the Control Problem. SOSM Algorithms . . . . 56

3.6 Conclusions . . . . . . . . . . . . . . . . 69

References .......................... 69

4 Assessment of SOSM Techniques Applied to Fuel Cells. Case Study: Electric Vehicle Stoichiometry Control . . . . . . . . . . . . . 73

4.1 Introduction . . . . . . . . . . . . . . . . 73

4.2 Succinct Description of the Electric Vehicle Fuel Cell System . . . 74

4.2.1 Air Compressor . . . . . . . . . . . . . . . 75

4.2.2 Air Supply Manifold . . . . . . . . . . . . . . 76

4.2.3 Air Humidifier and Temperature Conditioner Subsystems . 77

4.2 .4 Cathode Channels . . . . . . . . . . . . . . . . 77

4.2.5 Anode Channels . . . . . . . . . . . . . . 78

4.2.6 Water Model of the Polymeric Membrane . . . . . . . . 79

4.2 .7 Return Manifold . . . . . . . . . . . . . . . . 80

4.3 Electric Vehicle FCGS State Space Model for SOSM Control

Design ..................... . . 80

4.4 Control Objective and Sliding Surface . . . . . . . . . . . 82

4.5 Design of a SOSM Super-Twisting Controller for the Electric

Vehicle FCGS . . . . . . . . . . . . . . 85

4.6 SOSM Super-Twisting Controller Simulation Results . . . . . . 88

4.7 Comparison with Other Control Strategies . . . . . . . . . . . 93

4.7.1 Different SOSM Control Algorithms . . . . . . . . . 93

4.7 .2 LQR Controller . . . . . . . . . . . . . . . . 97

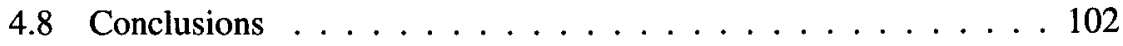

References . . . . . . . . . . . . . . . . . 102 
5 Control-Oriented Modelling and Experimental Validation

of a PEMFC Generation System . . . . . . . . . . . . . . . 105

5.1 Introduction . . . . . . . . . . . . . . 105

5.2 Air Compressor Subsystem . . . . . . . . . . . . . . 106

5.2.1 Air Compressor Motor Dynamic Equations . . . . . . . . 107

5.2.2 Diaphragm Vacuum Pump Characteristics . . . . . . . . 111

5.3 Air Supply Manifold Subsystem . . . . . . . . . . . . . . . . . 112

5.4 Air Humidification Subsystem . . . . . . . . . . . . . . . . 113

5.4 .1 Step $1 \ldots \ldots \ldots \ldots \ldots \ldots 114$

$5.4 .2 \operatorname{Step} 2 \ldots \ldots \ldots \ldots \ldots 115$

5.5 Fuel Cell Stack Flow Subsystem $\ldots \ldots \ldots \ldots$. . . . . 117

5.5.1 Cathode Channels . . . . . . . . . . . . . . 117

5.5.2 Anode Channels . . . . . . . . . . . . . . 120

5.5.3 Membrane Water Transport . . . . . . . . . . . . 121

5.6 Electrical Characterisation of the Fuel Cell Stack . . . . . . . . . 123

5.7 Conclusions . . . . . . . . . . . . . . 126

References . . . . . . . . . . . . . . . . . . 128

6 SOSM Controller for the PEMFC-Based Generation System.

Design and Implementation . . . . . . . . . . . . . . . . . 129

6.1 Introduction . . . . . . . . . . . . . . . . . . . . . . . . 129

6.2 State Space Model of the Experimental Fuel Cell System for

Control Design . . . . . . . . . . . . . . . . . . . 129

6.2 .1 Control Output . . . . . . . . . . . . . 133

6.2 .2 Auxiliary Functions . . . . . . . . . . . . . 133

6.3 Control Objective . . . . . . . . . . . . . . . . . . . . 134

6.4 Controller Synthesis . . . . . . . . . . . . . . . . . . 137

6.4 .1 Super-Twisting Algorithm . . . . . . . . . . 139

6.4 .2 Twisting Algorithm . . . . . . . . . . . . . 140

6.4 .3 Sub-Optimal Algorithm . . . . . . . . . . . . 140

6.4 .4 Feedforward Term . . . . . . . . . . . . . . . 141

6.5 Simulation Results . . . . . . . . . . . . . . . . . . . 141

6.6 Experimental Set-up of the PEM Fuel Cell System . . . . . . . . 143

6.7 Experimental Tests . . . . . . . . . . . . . . . . . . 144

6.7 .1 Regulation Tests . . . . . . . . . . . . . . 144

6.7 .2 Perturbation Tests . . . . . . . . . . . . . 148

6.8 Conclusions . . . . . . . . . . . . . . . 150

References ........................ 152

7 Conclusions, Open Lines and Further Reading . . . . . . . . . 153

7.1 Main Results . . . . . . . . . . . . . . . . . 153

7.2 Further Issues Related to PEMFC Control . . . . . . . . . . . 154

7.2.1 Adaptive Super-Twisting Algorithms . . . . . . . . . 154

7.2 .2 HOSM MIMO Control . . . . . . . . . . . . 155

7.2.3 Model Predictive Control . . . . . . . . . . . 155

7.2 .4 Observers for Internal Variables . . . . . . . . . 156 
7.3 Further Issues Related to Fuel-Cell-Based Systems . . . . . . . . 157

7.3.1 Hybrid Standalone Systems . . . . . . . . . . . . . 157

7.3.2 Distributed Generation Systems . . . . . . . . . . 157

References . . . . . . . . . . . . . . . . 158

Appendix A Electric Vehicle PEM Fuel Cell Stack Parameters . . . . . 161

A.1 Return Manifold Polynomial Fitting . . . . . . . . . . . . . . 161

A.2 Differential Equations Parameters . . . . . . . . . . . 161

A.3 Controller Parameters . . . . . . . . . . . . . . . 163

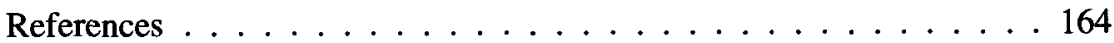

Appendix B Laboratory FC Generation System Parameters . . . . . . 165

Appendix C Laboratory FCGS State Space Functions and Coefficients 169

C.1 Expression of $\varphi(x, u, t) \ldots \ldots \ldots 16 \ldots \ldots \ldots$

C.2 Model Coefficients . . . . . . . . . . . . . 172

C.3 Feedforward Control Action . . . . . . . . . . . . 173

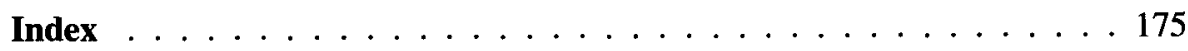

